Global Conferences Series:

Social Sciences, Education and Humanities (GCSSSEH), Volume 6, 2020

International Conference Fakultas Tarbiyah dan Keguruan Universitas Islam Negeri Imam Bonjol Padang (ICFTKUINIBP) 2020

DOI: https://doi.org/10.32698/icftk421

\title{
Teachers Blue Print Test Design in the Development of Learning Achievement Test
}

\section{Desain Tes Cetak Biru Guru Dalam Pengembangan Tes Prestasi Belajar}

\author{
Gusnita Efrina $^{\mathrm{a}}$, Ayu Rahma Nengsi ${ }^{\mathrm{b}}$, Yona Syaida Oktira ${ }^{\mathrm{a}}$ \\ ${ }^{a}$ Universitas Nahdatul Ulama Sumatera Barat, Indonesia, ${ }^{b}$ Institute Agama Islam Negeri Takengon, Aceh, \\ Indonesia \\ E-mail: rahmanengsiayu@gmail.com
}

\begin{abstract}
The study was aimed to explain the field phenomenon, observing the way teachers prepare test blue print. This research is a qualitative method, the researcher is a key instrument in data collection. Triangulation techniques are used in collecting field data, as well as testing the credibility of the data. The research subjects were taken by using purposive sampling technique, namely 4 elementary school teachers. The research data were analyzed using the Miles and Huberman model, namely: reduction, display and conclusion. The results of the research findings clearly describe each step taken by the teacher in designing the test blue print. There are two main points to look at, are 1) determining the dimensions that are used as references in developing test items and 2) making specification tables as basic guidelines. The initial steps taken are quite appropriate, starting from determining the dimensions in the form of competency standards, basic competencies and indicators referred to from the curriculum. Whereas in the preparation of the specification table, several things were found, namely: a) there are differences in understanding of the aspects that must be in the table, b) the cognitive domain is not visible in the specification table, c) the teacher does not understand the importance of the cognitive domain in test design.
\end{abstract}

Keywords: Design blue print teacher-based test, achievement test

\section{PENDAHULUAN}

Standar nasional pendidikan (SNP) memiliki beberapa lingkup, diantaranya yaitu standar penilaian. Kegiatan penilaian penting dilakukan untuk menjamin dan pengendalian mutu pendidikan (peraturan pemerintah No 19 tahun 2005). Dalam rangka menjamin mutu pendidikan tersebut, dilakukan dua jenis evaluasi yaitu evaluasi oleh satuan pendidikan dan evaluasi terhadap pengelola pendidikan itu sendiri. Salah satu evaluasi yang dilakukan oleh satuan pendidikan berupa evaluasi hasil belajar siswa. Evaluasi merupakan sebuah proses dalam memberikan nilai terhadap objek yang jadi sasaran penilaian, dimana hasil penilaian tersebut dijadikan sebagai dasar dalam pengambilan keputusan (Yusuf . 2015).

Secara umum ada empat fungsi evaluasi pendidikan yaitu: fungsi diagnostic, fungsi penempatan, fungsi formatif dan fungsi sumatif (Azwar.2010). Dalam melakukan keempat fungsi evaluasi tersebut, diperlukan intrumen a untuk mengukur dan memberikan informasi yang dibutuhkan. Dalam hal ini Intrumen yang dimaksud merujuk pada tes prestasi belajar. Benar dan berkualitasnya informasi yang diterima ditentukan oleh kualitas tes yang dipakai untuk mengukur. Tes yang dirancang dengan prosedur yang benar akan memberikan informasi yang tepat dan sebaliknya, bila tes dikembangkan dengan tidak taat pada prosedur yang dianjurkan maka informasi yang diberikan oleh hasil pengukuran tes tersebut belum tentu valid (Azwar.2010).

Otonomi daerah yang terjadi sekarang mengharuskan setiap institusi pendidikan menyusun tes prestasi sendiri dalam melakukan evaluasi. Hal ini berarti perangkat tes, dibuat oleh guru mata pelajaran yang tergabung dalam kelompok kerja perwilayah (Suyata, Mardapi, Kartowagiran. 2010). Sebagai hasilnya perangkat tes yang dirancang belum tentu memberikan informasi yang benar dan valid dalam evaluasi hasil belajar siswa, hal ini berakibat keputusan pendidikan yang diambil menjadi tidak tepat sasaran.

Copyright (C) 2020, the Authors. Published by Redwhite Press. 
Banyak studi penelitian dilakukan terkait kualitas tes prestasi buatan guru, hampir semua temuan penelitian menjelaskan lemahnya kualitas hasil pengukuran dari intrumen tersebut. Banyak faktor yang menjadi penyebabnya, diantaranya rata-rata guru tidak memiliki keterampilan yang memadai dalam mengembangkan tes sesuai dengan prosedur yang layak. Tidak ada ujicoba maupun analisis tehadap kualitas butir tes yang telah dirancang, soal yang dibuat merupakan duplikasi soal terdahulu, tidak membuat blue print sebagai panduan menulis soal, dan sebagainya (Zamsir. 2010).

Prasurvei awal yang dilakukan pada kegiatan FGD guru kelas VI Sekolah Dasar di Kab. Padang Pariaman disimpulkan hampir semua guru yang tergabung dalam kegiatan tersebut belum memiliki kompetensi yang memadai dalam menyusun tes yang layak. Para guru mengeluhkan sulitnya merancang tes prestasi, apalagi melakukan ujicoba dan analisis akan membutuhkan tenaga dan biaya yang besar. Ketika ditanya kriteria butir tes yang baik, tidak ada satupun guru yang faham mengenai hal tersebut. Tidak banyak pelatihan diperoleh, tidak tersedianya buku panduan perancangan tes yang bisa digunakan secara praktis oleh guru disekolah, menjadi alasan utama ketidakmampuan mereka dalam merancang tes yang berkualitas.

Persoalan diatas menjelaskan urgennya kondisi terus yang terjadi secara berulang-ulang, tanpa ada perubahan kearah yang benar terkait cara guru dalam mengembangkan tes prestasi yang layak. Karena itu penting dilakukan penelitian guna memberikan gambaran secara nyata aktivitas yang terjadi dilapangan. Bagaimana cara mereka merancang tes prestasi belajar khususnya pada perancangan test blue perint atau tabel spesifikasi sebagai pedoman dalam menulis butir tes. Tabel spesifikasi merupakan format yang berisi informasi tentang suatu butir tes dan dijadikan sebagai landasan untuk menulis butir tes menjadi sebuah perangkat tes. Jadi fungsi test blue print adalah sebagai pedoman dalam pengembangan sebuah tes prestasi belajar.

Penelitian ini penting untuk dilakukan karena, temuan penelitian ini memberikan informasi yang dibutuhkan terkait cara yang ditempuh oleh guru, dalam mengembangkan intrumen tes prestasi siswa. Khususnya pada penyusunan table spesifikasi tes atau table blue print sebagai dasar awal dalam menulis butir tes yang komprehensif.

\section{METODE}

Penelitian ini merupakan penelitian kualitatif yang mengkaji situasi sosial (Sugiyono. 2010) terkait pelaku, tempat dan aktivitas yang berlangsung dalam proses pendidikan. Tahapan penelitian ini yaitu peneliti melakukan observasi kelapangan (Grand Tour untuk memahami gambaran situasi secara umum. Setelah menemukan fokus penelitian yang urgen, terkait kegiatan evaluasi hasil belajar siswa, maka dilakukan penelitian dengan teknik triangulasi agar data yang diperoleh bersifat meluas dan dapat meningkatkan pemahaman peneliti terhadap temuan yang diperoleh.

Peneliti mengikuti kegiatan FGD guru mata pelajaran yang ada di wilayah kerja tertentu di Kab Padang Pariaman. Selama mengikuti kegiatan FGD tersebut, peneliti melakukan observasi dan wawancara dengan guru-guru yang terlibat di dalam forum. Observasi dilakukan secara mendalam dan mendokumentasikan setiap aktivitas yang terjadi. Membuat catatan anekdot mengenai kejadian-kejadian luar biasa ketika diskusi berlangsung. Kegiatan wawancara dilakukan untuk mendapatkan temuan penelitian secara lebih mendalam.

Penentuan sampel dalam penelitian kualitatif ini, dilakukan ketika memasuki lapangan dan selama proses penelitian berlangsung. Namun secara umum yang menjadi partisipan atau informan penelitian adalah guru yang ikut serta dalam pembuatan perangkat tes prestasi belajar. Penentuan guru yang dipilih jadi narasumber ditentukan secara purposive dengan pertimbangan tertentu. Secara spesifik informan yang akan diwawancarai yaitu, guru yang dipandang secara aktif terlibat dalam pembuatan soal ujian baik formatif maupun sumatif. Serta beberapa guru yang ikut diskusi FGD rutin, walaupun tidak ditunjuk sebagai anggota tim perancang perangkat tes sumatif, tetapi juga membuat soal ulangan harian dikelas yang mereka ampu masing-masing. Pemilihan dengan cara tersebut dilakukan dengan alasan agar data yang diperoleh berimbang, serta sesuai dengan kondisi sebenarnya. secara pasti jumlah guru yang terus diobservasi secara mendalam sebanyak 4 orang guru kelas VI sekolah dasar.

Peneliti adalah intrumen kunci yang terjun langsung kelapangan sebagai observer dengan menggunakan teknik observasi terstruktur. Peneliti akan terus mengikuti kegiatan FGD rutin yang diselenggarakan oleh tim musyawarah guru mata pelajaran (MGMP), mendukumentasikannya, membuat cacatan anekdot terkait kejadian unik dan khusus sambil terus mengikuti dan mengamati proses yang berlangsung. Ketika data penelitian yang dikumpulkan sudah jenuh, atau tidak ditemukan kejadian unik lainya yang terjadi selama FGD, temuan yang sama diperoleh setiap kali mengikuti diskusi tersebut, disaat itulah data penelitian dianggap telah cukup dan berhenti mengikuti FDG. 
Semua data hasil penelitian yang dikumpulkan dilapangan akan di analisis menggunakan model Miles dan Huberman dengan tiga cara (Sugiyono. 2010) yaitu: (1) Reduksi data (data reduction): tahap reduksi data dilakukan dengan cara data yang telah dikumpulkan selama proses penelitian dikelompokkan pada pokokpokok penting tertentu dengan tujuan dapat memberikan gambaran yang lebih jelas terhadap temuan lapangan; (2 Penyajian data (data display): pada tahap ini data yang telah dipilah-pilah dan dikategorikan akan disajikan dalam bentuk uraian ataupun bagan sehingga mudah untuk dipahami hubungan antar kategori dan ditemukan polanya; (3 Kesimpulan (conclusion): tahap kesimpulan merupakan temuan dari hasil penelitian yang didukung oleh bukti-bukti fakta dan fenomena lapangan.

\section{HASIL DAN PEMBAHASAN}

Dalam pengembangan tes prestasi belajar siswa, mendisain test blue print atau dikenal juga dengan sebutan tabel spesifikasi tes, merupakan fondasi penting dalam prosedur pengembangan perangkat tes (Mahaputri, Dantes, Sadia. 2013). Penyusuan blue print menjadi sangat penting, ketika tabel tersebut menjadi acuan untuk merancang butir tes.

Tabel spesifikasi hendaknya memenuhi syarat: (1) mewakili isi kurikulum yang akan diujikan (Wiliam, D. et al. 2010), (2) indikator yang dibuat rinci, jelas dan terukur dengan kata operasional yang jelas (Yew, Dawood and Narayansany. 2015) (3) soal-soal yang direncanakan dimungkinkan dapat dibuat sesuai dengan indikator yang direncanakan dalam kisi-kisi itu (Susetyo. 2013). Mendesain blue print dengan benar, akan memandu pembuatan butir yang tepat dalam mengukur tingkatan kognitif siswa. Dimana test blue print, merupakan rujukan dasar ketika membuat butir soal yang komprehensif mewakili semua materi, dan pengukuran domain kognitif taksonomi bloom (pengetahuan, pemahaman, aplikasi analisis, evaluasi dan create).

Temuan penelitian lapangan, menunjukkan secara jelas cara guru dalam mendisain test blue print, dalam penyusunan intrumen tes prestasi belajar siswa. Berikut dijelaskan hasil penelitian sesuai dengan Teknik trianggulasi yang ditempuh selama penelitian lapangan

Hasil observasi

Observasi lapangan dilakukan ketika mengikuti kegiatan kelompok kerja guru sekolah dasar di wilayah 1 Kec. Lubuk Alung, Kab, Padang Pariaman. Observasi dilakukan dengan cara partisipasi pasif, peneliti hanya mengamati kegiatan yang berlangsung, tetapi tidak ikut terlibat dalam kegiatan tersebut. Langkah pengembangan test blue print yang ditempuh guru, dikelompokkan dalam tabel berikut:

Tabel 1. Cara guru dalam mendisain test blue print

\begin{tabular}{|c|c|c|}
\hline No & Tahapan & Kegiatan \\
\hline 1 & Penentuan dimensi & $\begin{array}{l}\text { Menentukan: } \\
\text { a) Standar kompetesi } \\
\text { b) Kompetensi dasar } \\
\text { c) Indicator }\end{array}$ \\
\hline 2 & Pembuatan test blue print & $\begin{array}{l}\text { a) Pembuatan tabel spesifikasi lengkap dengan penyebaran } \\
\text { butir tes } \\
\text { b) Penentuan jumlah butir yang akan dibuat }\end{array}$ \\
\hline
\end{tabular}

Sumber: observasi lapangan

Terlihat ada dua langkah yang ditempuh guru dalam mendisain tabel spesifikasi, pada pengembangan tes prestasi belajar siswa. Secara umum terlihat telah mengikuti alur yang benar dan juga terlihat beberapa aspek yang seharusnya ada namun terlewatkan, karena banyak factor yang menjadi penyebabnya, salah satunya ketidak fahaman guru yang bersangkutan. Berikut dijelaskan dengan lebih rinci setiap langkah tersebut:

\section{Penentuan dimensi}

Tahap awal yang ditempuh, dalam mengembangkan butir tes dimulai dari menentukan dimensi yang jadi rujukan berupa Standar Kompetensi (SK), kompetensi dasar (KD) dan indikator. SK dan KD dirujuk langsung dari kurikulum nasional. Berdasarkan 4 orang guru yang diobservasi secara berkala, 1 orang diantara mereka mengembangkan lagi indikator yang telah ditentukan dalam kurikulum. Sehingga indikator dalam tabel spesifikasi yag dibuat menjadi lebih rinci berdasarkan materi yang diajarkan. 


\section{Pembuatan test blue print (tabel spesifikasi) sebagai pedoman dasar}

Pada penyusunan tabel spesifikasi, semua guru yang diamati membuat tabel spesifikasi berdasarkan pelatihan yang diikuti pada kegiatan kelompok kerja guru. Ditemukan beberapa fenomena dalam pengembangan tabel spesifikasi tersebut diantarannya:

a) Keterampilan dan pengetahuan setiap guru dalam mengembangkan tabel spesifikasi tes prestasi belajar ternyata tidak sama.

Terlihat dari 1 diantara 4 orang guru yang diamati, lebih menjabarkan indikator yang dirujuk, dan merumuskan lagi indikator sesuai KD yang ada menjadi lebih rinci, spesifik dan terukur. Sedangkan 3 diantaranya hanya merujuk indikator yang telah disediakan oleh kurikulum nasional tanpa ada pengembangan lebih detail sesuai dengan materi yang diajarkan. Memang tidak ada yang keliru dari hal ini, namun dengan lebih spesifik, terukur dan menggunakan kata kerja operasional dalam pengembangan akan lebih memudahkan dalam pembuatan butir tes yang dapat mengukur kemampuan tertentu peserta didik sesuai dengan KD yang dikur (Susetyo.2015)

b) Domain kognitif belum tampak dalam table spesifikasi

Dari ke empat 4 orang guru yang diamati belum tampak ada yang menjabarkan tingkatan domain kognitif yang ingin diukur sesuai taksonomi bloom. Dalam tebel spesifikasi yang dibuat hanya dijabarkan SK, KD dan indikator serta lengkap dengan penyebaran nomor soal pada setiap indikator beserta jumlah soal.

c) Terkait penyebaran jumlah butir soal dalam tabel spesifikasi, terlihat setiap satu indikator dibuat satu butir soal bahkan lebih tergantung kedalaman materi.

\section{Hasil wawancara}

Wawancara diperoleh dari 4 orang guru sekolah dasar, yang ikut terlibat dalam pembuatan soal mata pelajaran untuk ujian tengah dan akhir semester di wilayah 1 kec. Lubuk alung, kab. Padang pariaman. Wawancara tidak dilakukan secara khusus tetapi dilakukan secara bersamaan dengan proses observasi secara berkala yang dilakukan terhadap ke 4 orang narasumber tersebut.

Hasil wawancara menegaskan temuan yang diperoleh selama proses observasi terkait cara guru dalam mendisain test blue print. Berikut rangkuman dari hasil wawancara:

a) Tidak tampaknya domain taksonomi bloom dalam disain tabel spesifikasi yang dibuat oleh guru.

b) Mereka kurang familiar dengan pembuatan perangkat tes yang menggunakan taksonomi bloom, karena jarang dibuat sebelumnya.

c) Masih banyak guru tidak faham cara memasukkan domain taksonomi bloom dalam tabel spesifikasi

d) Mereka juga merasa kebingunan cara membuat butir soal nantinya yang sesuai dengan tingkatan taksonomi bloom tersebut.

e) Para guru lebih suka mengambil tabel spesifikasi lama yang telah ada, tanpa ada revisi selama kurikulum masih sama (SK, KD, indikator) untuk suatu mata pelajaran. Jika ada perubahan terhadap SK, KD ataupun indikator, maka baru disusun tabel spesifikasi yang baru sesuai kebutuhan. Terkait persoalan ini alasan yang dikemukakan pun bervariasi berupa: membuang banyak waktu dan tenaga untuk merevisinya, tidak perlu ada revisi terhadap tabel spesifikasi yang harus direvisi adalah butir soalnnya.

\section{Hasil dokumentasi}

Dukumentasi data juga dilakukan selama proses penelitian. Dokumentasi dilakukan pada saat grand tour observasi Ketika peneliti mendapatkan kesempatan mengikuti kegiatan pertemuan kelompok kerja guru pada pertengahan Februari 2020 di Kec. Lubuk Alung, Kab.Padang Pariaman. Dukomentasi yang dikumpulkan berupa desain tabel spesifikasi tes (test blue print) yang telah dibuat oleh guru pada semester yang tela berlalu. Berikut dokumen tabel spesifikasi yang diperoleh

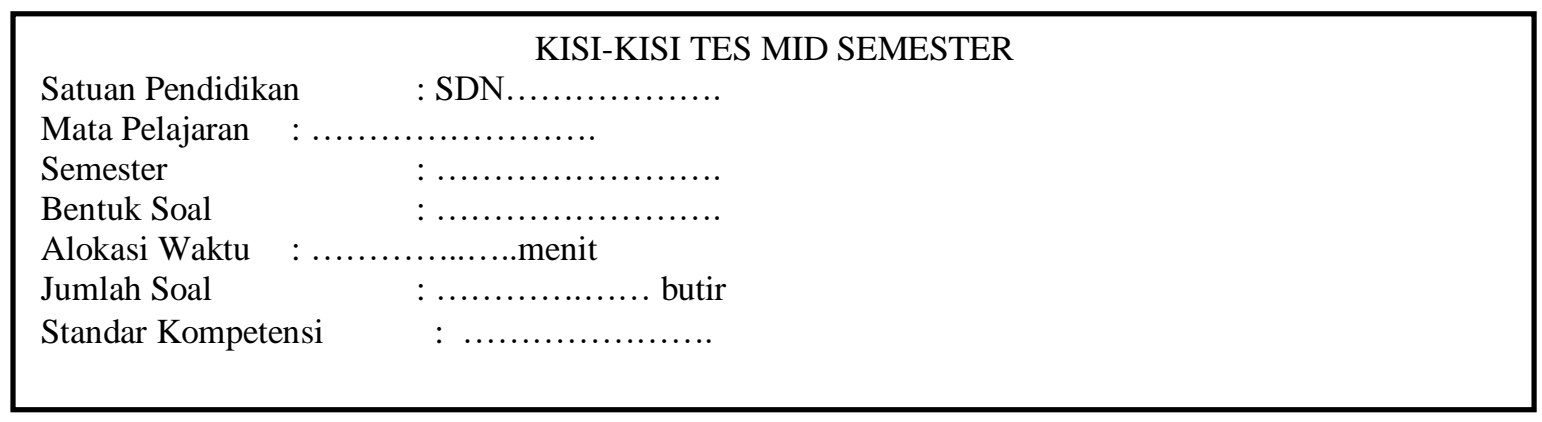


Tabel 2. Kisi-kisi Tes Ujian MID Semester Mata Pelajaran

\begin{tabular}{|c|c|c|c|c|}
\hline $\begin{array}{c}\text { Kompetensi } \\
\text { dasar }\end{array}$ & Materi & Indikator & No Soal & Jumlah Soal \\
\hline
\end{tabular}

Sumber: dokumentasi sekolah

Dokementasi memberikan gambaran yang jelas mengenai disain tabel spesifikasi tes atau test blue print buatan guru, yang digunakan sebagai pedoman dalam merancang butir tes menjadi suatu perangkat tes prestasi hasil belajar. Tidak terlihat adanya pengukuran terhadap penguasaan aspek kognitif sesuai domain taksonomi bloom.

\section{SIMPULAN}

Berdasarkan jabaran dari temuan hasil penelitian, dapat disimpulkan sebagai berikut: (1) Secara umum para guru cukup mampu dalam mendisain tabel test blue print, dan perlu perbaikan pada bagian menambahkan tingkatan taksonomi bloom dalam tabel spesifikasi guna mengukur wujud kemampuan kognitif. (2) Tidak semua guru membuat tabel spesifikasi yang baru, ataupun melakukan revisi terhadap tabel spesifikasi yang lama jika digunakan untuk pembuatan soal ujian mid atau semester. (3) Dalam membuat tabel spesifikasi guru merujuk dimensi yang akan diukur berdasarkan standar kompetensi dan kompetensi yang telah ditetapkan dalam kurikulum nasional. baik itu mengambil penuh semua indikator yang telah ditetapkan dalam kurikulum dan ada juga yang melakukan pengembangan indikator agar semakin mudah untuk mengukur kemampuan siswa pada materi yang telah diajarkan.

\section{REFERENSI}

Azwar, Saiffudin. (2010). Tes prestasi: Fungsi Dan Pengembangan Pengukuran Prestasi Belajar. 2010: Pustaka Pelajar

Mahaputri ,Ni Luh Putu. Dantes, Nyoman, Sadia, I Wayan. (2013). Pengembangan Tes Prestasi Belajar Berbasis Taksonomi Anderson Dan Krathwohl Pada Kompetensi Dasar Fisika Smk Kelas X Semester Ganjil Se-Kota Singaraja. e-Journal Program Pascasarjana Universitas Pendidikan Ganesha. Vol.3

Sugiyono. (2010). Penelitian kualitatif, kuantitatif dan D\&R. Bandung: Alfabeta

Suyata. Mardapi, Djemari. Kartowagiran, Badrun. (2010). Identifikasi Need Assessment: Studi Awal Model Pengembangan Bank Soal Berbasis Guru Di Provinsi DIY. Jurnal Pendidikan. Mei; 40 (1): 45-58

Susetyo, Budi. Prosedur Penyusunan Dan Analisis Tes. 2015. Bandung: PT Refika Aditya

Wiliam, D. et al. (2010) 'Teachers developing assessment for learning: impact on student achievement Teachers developing assessment for learning: impact on student achievement'. doi: 10.1080/0969594042000208994

Yusuf, Muri. A. (2015). ASSESMEN dan Evaluasi Pendidikan. Jakarta : KENCANA

Yew, T. M., Dawood, F. K. P. and Narayansany, S. (2015) 'Designing an Instrument for Providing Better Student Feedback on Teaching Effectiveness', 3(1), pp. 14-22.

Zamsir. (2010). Kualitas tes buatan guru matematika SLTP negeri di kota madya kendari. Jurnal pendidikan matematika dan sains. Vol.2. 65-69 